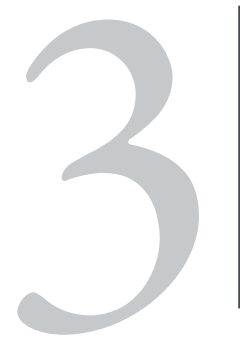

\title{
EVALUACIÓN DE LAS CARACTERÍSTICAS DEL IMPUESTO PREDIAL EN MÉXICO
}

\author{
PROPERTY TAX IN MEXICO: AN \\ EVALUATION BASED ON PRINCIPAL \\ ASPECTS
}

Ignacio Ruelas Ávila ${ }^{1}$

Recibido: 24/03/2015

Publicado: 20/07/2015

\section{RE S U M E N}

El impuesto predial es la principal fuente tributaria de ingresos de los municipios de México. Motivado por lo anterior, y con el objetivo de hacer una aproximación a la capacidad fiscal y las competencias tributarias de los municipios mexicanos, en el presente trabajo se evalúa la eficiencia, la suficiencia, la responsabilidad política, la simplicidad administrativa y la justicia distributiva del predial. Los resultados dan cuenta de las disparidades y las dificultades técnicas e institucionales que la mayoría de los municipios enfrentan para recaudar y administrar este impuesto. Aunado a lo anterior, en el siguiente trabajo se discuten desafíos en materia de equidad territorial y distributiva.

Dados los tropiezos en el camino, la idea de enmarcar la descentralización en un proceso de regionalización surge como una nueva posibilidad. No obstante, se discuten limitaciones fiscales, institucionales y políticas que deben tomarse en cuenta si se desea lograr un proceso exitoso.

\section{PA L A R A S C L AVES}

impuesto predial, gobiernos municipales, ingresos municipales, servicios públicos locales, federalismo fiscal. 


\section{A B S T R A C T}

The property tax is the most important tax source for mexican local governments. So, according to the economic literature, this paper analizes the efficiency, sufficiency, political responsibility, administrative simplicity and distributive justice of property tax as a local tax. As a result, we infer difficulties and disparities faced by local governments for collect and manage this tax. Furthermore, this work discuss challenges about territorial and distributional equity

\section{K E Y W O R D S}

property tax, local governments, local revenues, local public services, fiscal federalism.

\section{I N T R O D U C C I Ó N}

El impuesto predial es el principal instrumento tributario de generación de recursos fiscales propios en los municipios de México. Su alta participación dentro de los ingresos tributarios así lo constata. En contraparte, al compararlo respecto a los ingresos municipales totales, la importancia se reduce en demasía dejando entrever una constante dependencia a las transferencias gubernamentales del gobierno federal.

Como se observa en el siguiente gráfico, la recaudación del impuesto predial respecto a los ingresos totales muestra cierta irrelevancia en el tiempo. Considerando el periodo de 1989 al 2013, este impuesto representa, en promedio, apenas el 7\% de los ingresos totales de los municipios. 
GRÁFICO 1

COMPOSICIÓN DE LOS INGRESOS TOTALES MUNICIPALES

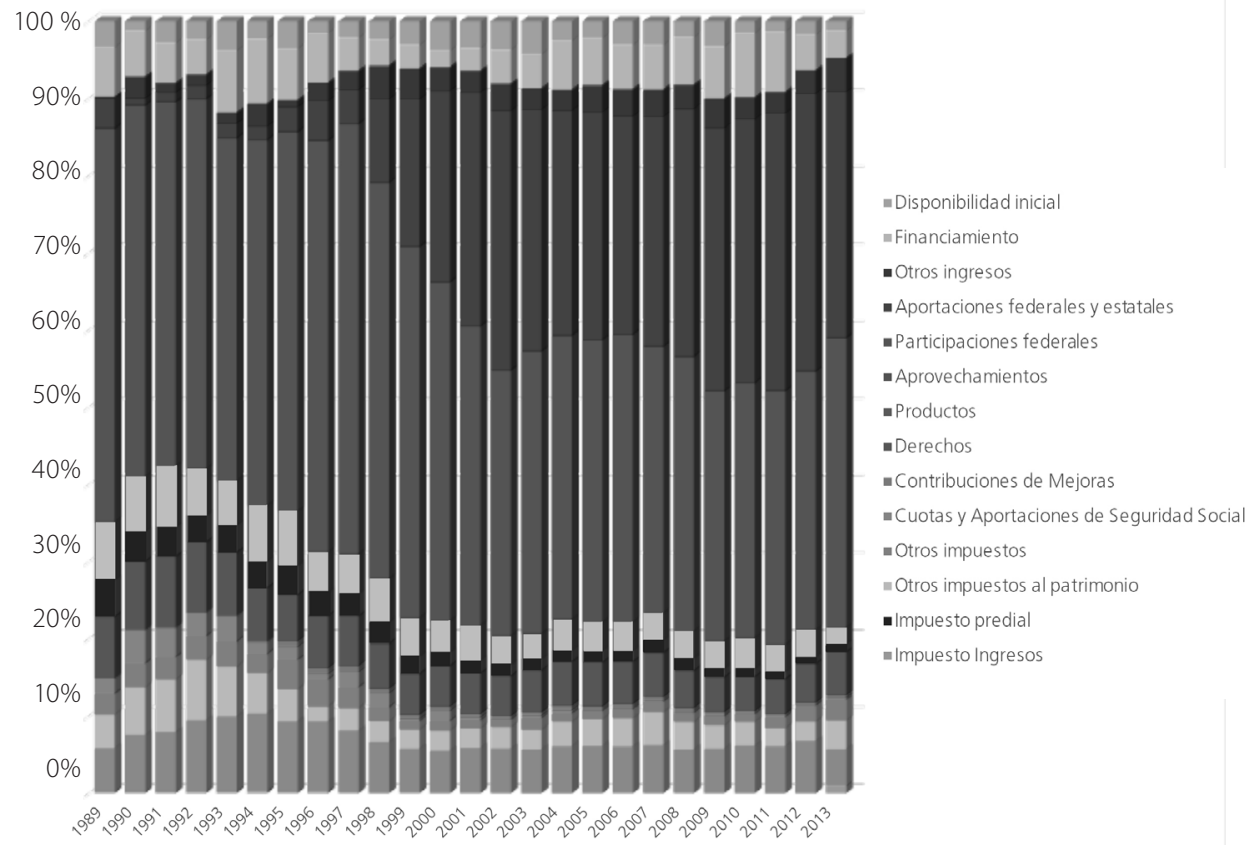

FUENTE: ELABORACIÓN PROPIA CON DATOS DEL INEGI. ESTADÍSTICAS DE FINANZAS PÚBLICAS ESTATALES Y MUNICIPALES.

Respecto al tema tributario, la recaudación de impuestos municipales representa cerca del 13\% de los ingresos totales presupuestados en los municipios. El 55\% del total de los impuestos recaudados corresponde al predial.

\section{GRÁFICO 2}

\section{EVOLUCIÓN DE LA PARTICIPACIÓN DEL PREDIAL EN LOS IMPUESTOS E INGRESOS MUNICIPALES}

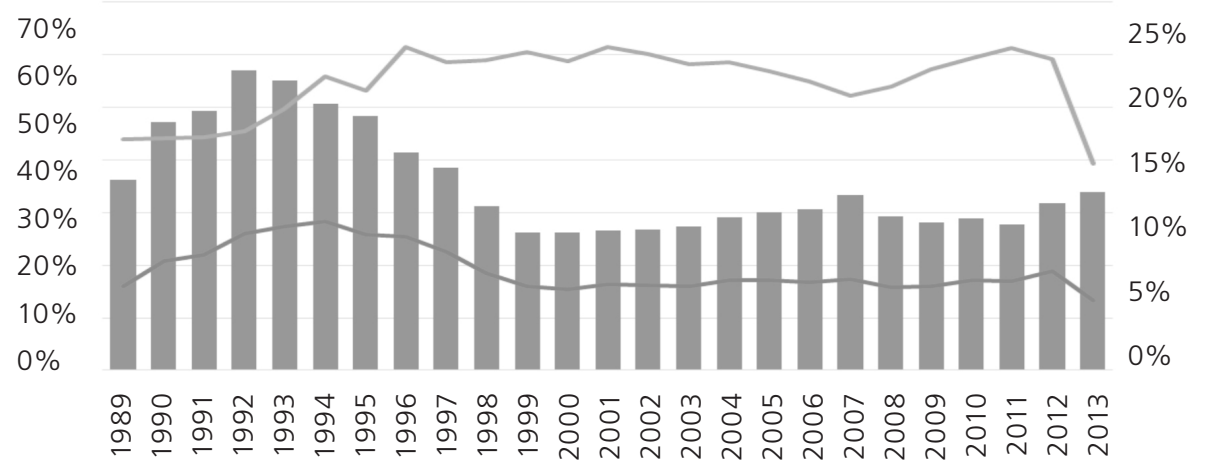

\footnotetext{
Importancia impuestos/ ingresos (eje derecho) 
La evolución de la participación del predial nos permite afirmar que, a pesar de su poca participación en los ingresos, históricamente este impuesto ha sido el principal instrumento tributario de generación de ingresos propios municipales. Pero no sólo eso, hay evidencia que muestra que también ha sido el principal instrumento para gravar el patrimonio y la riqueza en México.

TABLA 1

ESTRUCTURA DE LA RECAUDACIÓN DE LOS IMPUESTOS AL
PATRIMONIO EN MÉXICO (COMO PORCENTAJE DEL PIB)

\begin{tabular}{llllllll} 
& 1990 & 1995 & 2000 & 2005 & 2010 & 2012 \\
\hline $\begin{array}{l}\text { Patrimonio } \\
\text { Predial }\end{array}$ & $\mathbf{0 . 2 3 2}$ & $\mathbf{0 . 2 7 4}$ & $\mathbf{0 . 2 2 8}$ & $\mathbf{0 . 2 8 4}$ & $\mathbf{0 . 2 9 4}$ & $\mathbf{0 . 2 9 0}$ \\
Hogares & 0.126 & 0.198 & 0.162 & 0.177 & 0.194 & 0.203 \\
Riqueza neta & - & - & - & - & - & - \\
Individual & - & - & - & - & - & - \\
Corporativo & - & - & - & - & - & - \\
Estatal, herencia y donaciones & - & - & - & - & - & - \\
Estatal y herencias & 0.001 & 0.000 & 0.000 & 0.000 & 0.000 & 0.000 \\
Donaciones & 0.001 & 0.000 & - & - & - & - \\
Transacciones financieras y de capital & 0.105 & 0.077 & 0.065 & 0.108 & 0.100 & 0.088
\end{tabular}

FUENTE: ELABORACIÓN PROPIA CON DATOS EXTRAÍDOS DE OECD.STATS.

Como porcentaje del Producto Interno Bruto, la recaudación del predial en México asciende a $0.18 \%$, lo cual es considerablemente menor a lo recaudado por los países de la Organización para la Cooperación y Desarrollo Económico (OCDE) y por algunos países de América Latina ${ }^{2}$ (ver gráficos en el anexo).

Derivado de este contexto, en el presente trabajo se evalúa este impuesto con el objetivo de obtener evidencia que nos permita definir el grado en que el predial, así como la institucionalidad que lo rige, cumplen con las características fundamentales con las que, según la literatura económica, debiese contar un tributo.

Si bien más adelante se definen con mayor profundidad, las características que se discuten en este documento son las siguientes: eficiencia (recaudación y beneficio público), suficiencia (respecto al gasto público local), responsabilidad política (transparencia sobre cómo se gasta lo que se recauda), simplicidad administrativa y la justicia distributiva entre ciudadanos así como entre municipios.

2. Por ejemplo, Reino Unido y Canadá recaudan 20 veces más que México, mientras que Uruguay y Chile recaudan entre 5 y 3 veces más respectivamente. 
En términos metodológicos este trabajo es una aproximación descriptiva e inferencial sobre las capacidades fiscales y las competencias tributarias cuyo objetivo es validar lo siguiente:

1. El funcionamiento del impuesto predial no cuenta con un piso mínimo de eficiencia. Los municipios de México no logran recaudaciones estables y correspondientes a lo que anualmente presupuestan.

2. Es un impuesto cuya estrecha relación con el mercado hipotecario nos permite anticipar la distorsión de las decisiones económicas que éste provoca.

3. El predial no ha sido suficiente por sí mismo para financiar el gasto público local. La mayor suficiencia se encuentra en las transferencias del gobierno central.

4. No existen condiciones de responsabilidad política para transparentar lo que se presupuesta respecto al impuesto predial.

5. Los gobiernos municipales enfrentan problemas administrativos considerables que obstaculizan el funcionamiento de este impuesto.

6. Por ser un impuesto que grava el patrimonio de las personas, el predial es progresivo ya que contribuyen en mayor medida aquellas familias e individuos con mayor capacidad de hacerlo.

7. Al quedar en manos de los gobiernos municipales, el impuesto predial exacerba las diferencias territoriales, lo cual va en detrimento de la equidad horizontal.

El trabajo se limita únicamente a los más de 2,400 municipios de México. La heterogeneidad entre municipios, las reglas del juego entre instancias gubernamentales y el contexto socioeconómico del país en general limitan la extrapolación de los resultados. Asimismo, debido a que ya existe bastante evidencia al respecto -más adelante discutida-, en este trabajo no se buscan determinantes de las contribuciones de este impuesto. Este trabajo es una radiografía del impuesto predial con la cual se intenta complementar la discusión existente, además de aportar nuevos indicios en materia equidad distributiva y territorial.

El resto del trabajo se divide de la siguiente forma. En la segunda parte se describe brevemente la institucionalidad del predial en México. En la tercera parte se discute la teoría del impuesto y la evidencia empírica para México. En la cuarta parte se describe la metodología para evaluar cada una de las cinco características descritas. Esto como preámbulo para que en la quinta parte se analicen la eficiencia, suficiencia, responsabilidad política, la simplicidad y la justicia de este impuesto. Producto de la evaluación, en la última parte se desarrollan las conclusiones finales del trabajo. 


\section{INSTITUCIONALIDAD DEL PREDIAL EN MÉXICO}

De acuerdo con la Constitución Política de México (Artículo 115):

Los municipios administrarán libremente su hacienda, la cual se formará de los rendimientos de los bienes que les pertenezcan, así como de las contribuciones y otros ingresos que las legislaturas establezcan a su favor, y en todo caso:

a) Percibirán las contribuciones, incluyendo tasas adicionales, que establezcan los Estados sobre la propiedad inmobiliaria, de su fraccionamiento, división, consolidación, traslación y mejora así como las que tengan por base el cambio de valor de los inmuebles.

b) Los municipios podrán celebrar convenios con el Estado para que éste se haga cargo de algunas de las funciones relacionadas con la administración de esas contribuciones.

c) Percibirán las participaciones federales, que serán cubiertas por la Federación a los Municipios con arreglo a las bases, montos y plazos que anualmente se determinen por las Legislaturas de los Estados.

d) Percibirán los ingresos derivados de la prestación de servicios públicos a su cargo.

En efecto, el mismo Artículo 115 establece que los municipios tendrán a su cargo las siguientes funciones y servicios públicos.

a) Agua potable, drenaje, alcantarillado, tratamiento y disposición de sus aguas residuales;

b) Alumbrado público.

c) Limpia, recolección, traslado, tratamiento y disposición final de residuos;

d) Mercados y centrales de abasto.

e) Panteones.

f) Rastro.

g) Calles, parques y jardines y su equipamiento;

h) Seguridad pública, policía preventiva municipal y tránsito; y

i) Los demás que las Legislaturas locales determinen según las condiciones territoriales y socio-económicas de los Municipios, así como su capacidad administrativa y financiera.

En lo que respecta a las tasas, los municipios pueden proponer a las legislaturas estatales las cuotas y tarifas aplicables a impuestos, derechos, contribuciones de mejoras y las tablas de valores unitarios de suelo y construcciones que sirvan de base para el cobro del impuesto predial. Además, 
las legislaturas aprobarán los ingresos presupuestados por los municipios, revisarán y fiscalizarán sus cuentas públicas. El gasto presupuestado deberá ser aprobado por los propios municipios con base en sus ingresos disponibles y se ejercerá directamente por ellos mismos.

La recaudación del impuesto predial es producto de la tasa impositiva multiplicada por la base del tributo. Esto último depende directamente del valor catastral, el cual, en estricto sentido, debiese ajustarse a los valores de mercado. Tal como se mencionó arriba, la tasa puede ser propuesta por los municipios pero se aprueba en las legislaturas locales.

En suma, los municipios no tienen facultad plena para fijar las tasas del impuesto predial, cuentan con la posibilidad de celebrar convenios con los Estados de manera tal de compartir las tareas relacionadas con la administración de las contribuciones (actualización de avalúos, cobro, etcétera) y disponen del total de la recaudación para ejercer el gasto en las funciones y los servicios públicos señalados anteriormente.

\section{D ISCUSIÓN TEÓRICA Y EMPÍRICA SOBRE EL IM P UESTO PRED I A L}

\subsection{CONCEPTUALIZACIÓN DEL IMPUESTO A LOS BIENES INMUEBLES}

El impuesto predial es una imposición directa. Específicamente es un impuesto sobre el patrimonio de las personas. Afecta directamente a los recursos individuales, grava a personas naturales y jurídicas, y su base se encuentra en la riqueza de las personas. De acuerdo con Musgrave (1992), la justificación para los impuestos sobre el patrimonio se puede encontrar tanto en el principio del beneficio, como en el de la capacidad de pago. Por el lado del beneficio, el argumento recae en el hecho de que los servicios públicos incrementan el valor del patrimonio de las personas, lo cual las obliga a pagar por este incremento. Por el lado de la capacidad de pago, el patrimonio puede ser visto como un indicador de esa capacidad; por lo tanto, en teoría, las personas que cuentan con mayor capacidad de pago debieran pagar más por este tipo de tributos.

Este impuesto incide sobre un bien de alto valor económico: el inmueble. El hecho de que este tributo es sobre bases inmóviles permite evitar una mayor pérdida de ingresos. Intuitivamente genera una mayor facilidad de asignación de ingresos en el ámbito local; de igual forma, el inmueble es un bien de alta visibilidad, dificulta la evasión y permite usar el propio inmueble como garantía para el pago del impuesto. Puede usarse como medio 
de compensación al generar un monto tributario sobre contribuyentes ricos capaces de evitar la tributación sobre la renta.

La relativa inmovilidad de su base imponible brinda un mayor espacio para que las autoridades locales ajusten la carga sin grandes riesgos de relocalización de factores ni pérdidas de eficiencia (Bahl, 2009). Esta misma característica evita la exportación del impuesto a residentes de otras jurisdicciones, lo cual permite una cercana correspondencia entre los impuestos pagados por los contribuyentes y los beneficios recibidos por la provisión de servicios públicos, los cuales incidirían sobre la propiedad (Slack, 2010); es decir, este impuesto no agota su base fiscal, debido a que su recaudación se debiese gastar en mejoras que aumentan el valor de la propiedad, como: infraestructura urbana, alumbrado público, agua potable, alcantarillado y seguridad pública, entre las principales.

\subsection{DEFINICIÓN DE LAS PRINCIPALES CARACTERÍSTICAS DE UN IMPUESTO Y LA DISYUNTIVA ENTRE CENTRALIZACIÓN- DESCENTRALIZACIÓN DEL PREDIAL}

Desde Adam Smith y John Stuart Mill (1848) hasta Stiglitz (2003) se ha generado cierto consenso en la literatura sobre las principales características de los tributos, a saber:

1. Eficientes: la recaudación debe ser la máxima posible en la medida que las decisiones económicas de los individuos no sean distorsionadas.

2. Suficiente: su recaudación debe ser suficiente para financiar el gasto público.

3. Transparentes: las autoridades deben tener la responsabilidad política de transparentar 1) lo que se recauda y 2) dónde, cómo y en qué se gasta. Esto con el fin de que el ciudadano tenga elementos para evaluar si el uso de los recursos se apegan a sus necesidades y preferencias.

4. Sencillos de administrar: los costos de cobrar y administrarlos deben ser bajos.

5. Justo: que los impuestos afecten por igual a todos los ciudadanos y que, en proporción, pague más quien tiene mayor capacidad de hacerlo.

Con base en estas características, e intentando contraponer la descentralización y centralización del impuesto predial, a continuación se discuten argumentos provenientes de la literatura sobre el federalismo fiscal. Antes, se debe señalar que con total correspondencia a lo que señala la teoría económica, Richard Bird (2000) establece el siguiente marco normativo para los impuestos sub-nacionales:

- Éstos deben contar con bases inmóviles de forma tal de darle cierta libertad a las autoridades locales de mover las tasas sin disminuir sus bases. 
- Su recaudación debe coincidir con las necesidades locales.

- La recaudación debe ser estable y predictible en el tiempo.

- Sólo deben ser afectados los residentes locales.

- Deben contar con bases visibles de forma tal de asegurar la rendición de cuentas.

- Los residentes deben percibir justicia en el cobro.

- Deben ser fácil de administrar.

\subsection{EFICIENCIA}

El impuesto a la propiedad inmobiliaria debiese asignarse a instancias locales. Esto debido a que, a este nivel, las autoridades tienen una mayor cercanía con la población; lo cual les permite tener certeza acerca del pago que realiza el usuario por el hecho de tener una propiedad. En esta línea argumentativa, Charles Tiebout (1956) sostiene que las personas eligen dónde vivir, y por lo tanto están dispuestas a pagar por los servicios que se proveen; o en otras palabras, "votan con los pies". Por lo tanto, la eficiencia se encuentra en la localización de las personas y en la decisión fiscal de los gobiernos locales (Oates, 1969; Hamilton, 1976; Fischell, 2001). El "principio de equivalencia fiscal" sugerido por Olson (1969) refuerza esto último estableciendo que se deberían pagar impuestos a cada nivel correspondiente a los beneficios que se reciben de cada jurisdicción. En cuestión de eficiencia, la discusión se inclina por la descentralización de este impuesto.

\subsection{SUFICIENCIA}

El marco normativo del federalismo fiscal, señalado anteriormente, establece que los impuestos cuya base es inmóvil permiten tener mayor control en su registro y cobro, lo cual permite intuir que el impuesto predial tiene gran potencial de recaudo (Norregaard, 2010), de manera que podría promover el financiamiento autónomo de servicios y bienes públicos locales y reducir la dependencia de las transferencias intergubernamentales. El flujo de ingresos provenientes del impuesto es estable en el tiempo y no presenta fluctuaciones drásticas ante los ciclos económicos. Esto facilita su predictibilidad, con réditos importantes para la planificación local del gasto futuro. Bonet, Muñóz y Mannheim (2014), citan literatura que señala que este impuesto es una fuente impositiva que no suele ser explotada ni apetecida por niveles más altos de gobierno (Bahl, Martínez-Vazquez y Youngman, 2010), lo cual hace menos factible que exista una competencia vertical por bases tributarias y sus resultantes efectos nocivos sobre el nivel óptimo del gasto público (Keen, 1998; Besley y Rosen, 1998). Con estos argumentos podríamos respaldar las competencias locales para manejar el impuesto predial. 


\subsection{SIMPLICIDAD ADMINISTRATIVA}

La capacidad de las autoridades para adecuar y recaudar este impuesto es un aspecto crucial de su funcionamiento. Bonet y otros (2014), señalan que la administración del impuesto a la propiedad inmobiliaria se basa en métodos relativamente científicos, dado que se emplean instrumentos rigurosos y metodologías sistemáticas para actividades clave como el mantenimiento del catastro y la valuación de las propiedades. En suma, estos son procesos complejos que requieren de instrumentos sofisticados, personal bien preparado y fuertes inversiones gubernamentales. En este sentido, Sepúlveda y Martínez Vázquez (2011), advierten que si el gobierno local no cuenta con la capacidad para llevar a cabo las tareas de recolección de información y de fiscalización, los ingresos recaudados son más sensibles a esta capacidad. Por el lado del contribuyente, Bahl, Martínez-Vázquez y Youngman (2010) sostienen que este impuesto impone bajos costos de cumplimiento, ya que estos no se involucran en determinar su obligación tributaria. Según lo discutido, y anticipando las diferencias en las capacidades institucionales y de gestión entre los gobiernos municipales, en materia administrativa el impuesto predial debería funcionar de forma más apropiada conforme las tareas catastrales y de valuación se centralizan.

\subsection{TRANSPARENCIA}

Uno de los propósitos generales de la descentralización política es generar una mejora en los procesos de rendición de cuentas ante la ciudadanía. Este argumento soportaría la implementación del impuesto a la propiedad inmobiliaria a nivel local. El argumento se puede asociar a lo propuesto por Tiebout (1956), quien afirma que a este nivel se produce un equilibrio en donde los consumidores se preocupan y exigen por los servicios públicos por los cuales ellos pagan; mientras que las autoridades se ven obligadas a hacerlo ante la disyuntiva de mantener el voto ciudadano. No obstante, no es hasta la Segunda Generación del Federalismo Fiscal en donde se alude a la responsabilidad política que enfrentan los gobiernos subnacionales para generar recursos propios. Esto debido a que un aumento en su autonomía fiscal se refleja principalmente en la rendición de cuentas de las autoridades ante la ciudadanía, la provisión de más y mejores servicios públicos y una menor propensión a caer en actos de corrupción (Weingast, 2008). La transparencia del impuesto promueve la rendición de cuentas por el uso de los recursos públicos, constituyendo un potencial incentivo a las autoridades locales para el mejoramiento de la infraestructura y los servicios en sus localidades.

Asimismo, se define como una propiedad favorable del impuesto su visibilidad, gracias a la cual el ciudadano puede evaluar con mayor claridad el 
costo que asume por la entrega de bienes y servicios públicos. Sin embargo, esta visibilidad pareciera un arma de doble filo. Según lo discutido en el trabajo de Bonet y otros (2014), esta visibilidad que tiene el pago directo anual, sin ser una contribución deducida de una fuente de ingresos ni escondida entre pagos indirectos, crea resistencia en los contribuyentes. Esta resistencia produce cierto desprecio por parte de las autoridades, por lo cual tratan de manipular el funcionamiento del impuesto de una manera que afecta la sostenibilidad en la generación de los recursos. Esta animadversión se manifiesta en acciones como la demora en formar el catastro, la escasa frecuencia de las valuaciones, la determinación de avalúos muy por debajo del precio de mercado y la decisión estratégica de establecer bajas tasas impositivas con respecto a jurisdicciones vecinas en el marco de la competencia fiscal. Si bien la literatura presenta grandes desafíos, se podría afirmar que en términos de transparencia existe un respaldo teórico a favor de la descentralización del impuesto predial.

\subsection{JUSTICIA}

Tal como se señaló anteriormente, uno de los principales beneficios del impuesto predial es que grava directamente el patrimonio de las personas, con lo cual se esperaría que contribuyan en mayor medida aquellas familias e individuos con mayor capacidad contributiva. A pesar de esta intuición, Simon (1943) sostiene que el impuesto a la propiedad es regresivo, ya que las personas de los sectores más pobres pagan más, en proporción a su ingreso, en comparación a los sectores más ricos. También se señala que el impuesto aumenta el precio de la propiedad construida y disminuye el acervo local de este bien. En contraargumento, en la actualidad se ha señalado que impuestos como el predial resultan estratégicos para introducir mayor progresividad en los sistemas impositivos de los países en desarro1 lo (Amarante y Jiménez, 2015). Empíricamente, existe evidencia que documenta tanto la regresividad de este tipo de impuestos (Chawla y Wannel, 2003) como su progresividad (Jorrat, 2009) ${ }^{3}$. En conclusión, en materia distributiva el impuesto predial tiene potencial para mejorar la redistribución del ingreso y la riqueza, no obstante a que esto dependerá del efecto de las contribuciones y la homogeneidad de los registros tributarios. Esto último resulta complejo si el funcionamiento del predial es descentralizado.

3. Se dice que un impuesto es progresivo cuando la mayor parte de la contribución total recae en la parte alta de la distribución de ingresos. Por el contrario, un impuesto resulta regresivo cuando la contribución recae en la parte baja. Es interesante ver que la evidencia existente responde a paises con características institucionales opuestas: el trabajo de Chawla y Wannel es para un país federal como Canadá, mientras que el trabajo de Jorrat es para un país centralizado como lo es Chile. 


\subsection{EVIDENCIA EMPÍRICA SOBRE EL PREDIAL EN MÉXICO}

La literatura empírica sobre el impuesto predial en México se ha enfocado prioritariamente en demostrar los factores que inciden en la recaudación del impuesto. Por el lado de las variables macroeconómicas se ha demostrado que el Producto Interno Bruto, los periodos de crisis y las decisiones de política fiscal son determinantes en el esfuerzo fiscal a nivel local (Broid, 2010; Sepúlveda y Martínez-Vásquez, 2011; Chávez, 2014) ${ }^{4}$. En línea con lo anterior, Chávez (2014) cita dos ejemplos concretos que ilustran las decisiones de política en materia del impuesto predial: en 2009 el Gobierno del Distrito Federal decidió condonar el impuesto predial a pequeñas y medianas empresas, buscando impulsar la competitividad y la protección del empleo, así como proteger el ingreso de las familias (Sánchez y Pérez, 2009); mientras que, en el mismo año, pero en Tijuana, el gobierno municipal decidió condonar las multas y recargos de este impuesto, con la misma intención de auxiliar la economía de los contribuyentes.

En cuanto a las variables microeconómicas, los trabajos han profundizado en factores como las características socioeconómicas, las transferencias intergubernamentales, los tipos de propiedad del bien inmueble, los periodos electorales y las capacidades institucionales y de gestión de los municipios. En primera instancia, realidades sociales como la marginación y la concentración del ingreso afectan negativamente la recaudación del predial (Broid, 2010; Ibarra, 2013, Bonet y Rueda, 2011; Ramírez y Erquizio, 2011; Aguilar, 2010; Gámez e Ibarra, 2009; Sour, 2008; Chávez, 2014).

Las transferencias intergubernamentales han generado una discusión metodológica interesante. Por un lado, existe evidencia sobre la dependencia financiera que generan estos recursos que provienen del gobierno central, lo cual va en detrimento del esfuerzo fiscal de los municipios (Broid, 2010; Sepúlveda y Martínez-Vásquez, 2011; Chávez, 2014). Cabrero (2010) explica que para las autoridades municipales, los costos de darle suficiencia al gasto público local con transferencias son menores que si se hiciera con impuestos. Ahora bien, específicamente para el caso mexicano, el mismo Broid (2010) desglosa el doble efecto de las transferencias: primero, las participaciones federales ${ }^{5}$, efectivamente, generan un incentivo que aumenta la recaudación; mientras que, en sentido inverso, conforme los municipios

4. No obstante a resultar significativas, generalmente estas variables son usadas más como controles para aislar fenómenos relacionados a causas más institucionales y socioeconómicas. El trabajo de Sepúlveda y Martínez Vásquez toma a 11 paises de América Latina, entre ellos México.

5. Las participaciones federales es un recurso, proveniente del $20 \%$ de la recaudación federal participable, que se distribuye a las entidades federativas y a los municipios, con base en una fórmula de distribución establecida en la Ley de Coordinación Fiscal. Su gasto no está condicionado. 
son más dependientes a las aportaciones, cuyo gasto está condicionado a un servicio público específico, su esfuerzo por recaudar es menor ${ }^{6}$.

Tomando como principal variable de interés el tipo de propiedad de los predios, Chávez (2014) demuestra que cuando los predios son comunales, la probabilidad de pagar el impuesto predial disminuye. Esto debido a la incertidumbre que se produce en esta situación, en donde la propiedad comunal es compartida por un grupo de personas, quienes en asamblea designan derechos de posesión por cierto periodo. Esto, señala el autor, le quita legitimidad al municipio para cobrar el predial, ya que deja de ser autoridad para asignar o retirar derechos. Además, como la distribución se realiza sin consultar al municipio, resulta aún más complicado identificar al contribuyente y el monto correspondiente que debiese pagar.

Los periodos de gobierno municipal, los cuales regularmente son de tres años, producen un sesgo orientado a acelerar el gasto público y recortar impuestos un año antes de que termine el periodo; esto con fines de obtener triunfos electorales y así consolidar la permanencia del partido por un periodo más. Moreno Jaimes (2007) e Ibarra (2013) se aproximan a esta conclusión, pero sólo tomando en cuenta a las entidades federativas. Broid (2010) y Chávez (2014) lo demuestran para los municipios y tomando como referencia el impuesto predial.

Respecto a las capacidades institucionales y de gestión, Cabrero (2004) demuestra que en las instancias municipales es en donde podemos encontrar los sistemas de rendición de cuentas más avanzados y confiables; pero, al mismo tiempo, los casos de menor transparencia e incapacidad administrativa también los podemos encontrar en este nivel de gobierno.

\subsection{CONCLUSIONES TEÓRICAS Y EMPÍRICAS SOBRE EL IMPUESTO PREDIAL}

En suma, una primera aproximación sustentada en la teoría nos permitiría aprobar al impuesto predial en materia de eficiencia y rendición de cuentas. En términos de suficiencia y simplicidad administrativa, se anticipan

6. El artículo 25 de la Ley de Coordinación Fiscal establece que la Federación aportará recursos a los estados y municipios denominados Fondos de Aportaciones Federales. El gasto de dichos recursos está condicionado a los siguientes objetivos:
1. Educación Básica y Normal
2. Servicios de Salud
3. Infraestructura Social
4. Fortalecimiento de los Municipios
5. Aportaciones Múltiples
6. Educación Tecnológica y de Adultos
7. Seguridad Pública de los Estados y del Distrito Federal
8. Fortalecimiento a las Entidades Federativas 
dificultades propias de la descentralización de este impuesto. En cuestión de equidad, debido a que los análisis no convergen y a que además para el predial en México no hay suficiente evidencia relacionada a su impacto distributivo, se esperaría que los resultados respondan más a la institucionalidad y a las capacidades instaladas de cada uno de los municipios.

Por su parte, la evidencia documentada para los municipios de México, nos aporta principalmente determinantes en la recaudación del impuesto. Con esto podemos argumentar que el impuesto predial responde al ciclo de la economía y su funcionamiento encuentra restricciones relacionadas con la desigualdad territorial, las transferencias intergubernamentales, el tipo de propiedad de los predios, la competencia electoral y las capacidades administrativas y de gestión.

Así pues, nuestra evaluación busca complementar esta evidencia con indicadores que muestren una radiografía del funcionamiento del predial.

\section{MÉTO D L OGÍA Y BASES DE DATOS}

En esta sección se describirá la metodología y los recursos utilizados para evaluar cada una de las características.

\section{1 EFICIENCIA}

Para evaluar esta característica, utilizando datos oficiales del Instituto Nacional de Estadística y Geografía (INEGI), se analizará la evolución de los niveles de recaudación del predial a precios constantes, así como los logros en la recaudación respecto a lo presupuestado por los gobiernos municipales. Con base en los datos de competitividad urbana elaborados por el Instituto Mexicano para la Competitividad, y con el fin de encontrar indicios sobre las decisiones que se puedan tomar en el mercado de viviendas, se calculará el grado de asociación entre la recaudación del predial y el mercado hipotecario, esto último medido en créditos otorgados (IMCO, 2014). Además, se utilizará el Censo Nacional de Gobiernos Municipales y Delegacionales (INEGI, 2013) para obtener indicadores relacionados a la distribución de servicios públicos que por ley le corresponden a los municipios y por ende debiesen financiarse localmente. Los principales indicadores que se derivan de la información recopilada son los siguientes:

- Tasa de crecimiento promedio desde 1989 y la desviación estándar correspondiente.

- Nivel de recaudación dentro del total programado por los municipios (porcentaje) 
- Coeficiente de correlación entre la recaudación del predial (percápita) y los créditos otorgados en el mercado hipotecario (percápita).

- Cobertura de servicios públicos en los municipios (porcentaje)

\subsection{SUFICIENCIA}

Para evaluar la suficiencia del predial respecto al gasto público se analizará la evolución del impuesto comparado con el gasto público local: gasto total, gasto corriente, gasto de capital y deuda pública. Con el fin de comparar el esfuerzo fiscal a través de la recaudación de este impuesto, se hará lo mismo para las transferencias provistas desde el gobierno central por concepto de participaciones y aportaciones federales.

Para esta característica, se utilizarán las definiciones de tipo de gasto establecidas por el Consejo Nacional de Armonización Contable (CONAC, 2010), a saber ${ }^{7}$ :

\section{Gasto Corriente}

Son los gastos de consumo o de operación, el arrendamiento de la propiedad y las transferencias otorgadas a los otros componentes institucionales del sistema económico para financiar gastos de esas características.

\section{Gasto de Capital}

Son los gastos destinados a la inversión de capital y las transferencias a los otros componentes institucionales del sistema económico que se efectúan para financiar gastos de éstos con tal propósito.

\section{Amortización de la deuda y disminución de pasivos}

Comprende la amortización de la deuda adquirida y disminución de pasivos con el sector privado, público y externo.

La información para construir estos indicadores proviene de las Estadísticas de Finanzas Públicas de los Estados y Municipios del INEGI. En suma, los indicadores serían los siguientes:

- Ratios sobre la suficiencia del impuesto predial respecto al gasto público local (porcentaje)

- Ratios sobre la suficiencia de las participaciones y las aportaciones federal respecto al gasto público local (porcentaje).

7. La coordinación de la contabilidad gubernamental en México está a cargo de este Consejo, el cual tiene por objeto la emisión de normas constables y lineamientos para la generación de información financiera que deberán aplicar los entes públicos, en sus tres ámbitos de gobierno (federal, estatal y municipal). 


\subsection{SIMPLICIDAD ADMINISTRATIVA.}

Este rubro se evaluará tomando como base de igual forma el Censo Nacional de Gobiernos Municipales y Delegacionales, ya que de éste se extraen indicadores relevantes sobre las tareas catastrales y de actualización.

Los indicadores que se derivan del análisis son los siguientes:

- Municipios con información catastral (porcentaje)

- Municipios con información catastral actualizada (porcentaje)

- Municipios con información catastral cuyos valores están actualizados conforme a valores de mercado (porcentaje)

- Municipios con acciones de modernización catastral emprendidas (porcentaje)

\subsection{RESPONSABILIDAD POLÍTICA}

Este punto se evaluará con el índice de transparencia presupuestaria construido por el Instituto Mexicano para la Competitividad (IMCO). Este índice es de 0 a 100 y mide la calidad de la información tanto en los presupuestos de egresos como de las leyes de ingresos aprobadas (IMCO, 2014). De este análisis se desprenden los siguientes indicadores:

- Índice de transparencia presupuestaria promedio de los municipios

- Municipios que alcanzaron índices aceptables en esta materia

\subsection{JUSTICIA}

\section{Equidad en la distribución de ingresos}

Para esta característica se utilizó la Encuesta de Ingresos y Gastos de los Hogares (INEGI, 2012). Esto porque dentro de sus variables se encuentra el gasto que los hogares realizan para el pago del impuesto predial y cuotas de servicio de conservación. Si bien se asume que al ser encuesta existe un alto margen de error debido a la veracidad de la información declarada, la idea es obtener un proxy del impacto que tiene el pago del impuesto en la distribución de ingresos de los hogares.

Para evaluar el impacto del predial en la distribución del ingreso se utilizarán específicamente los siguientes indicadores:

- Distribución del pago del predial por deciles de ingreso percápita

- Tasa media del impuesto predial

- Índice de Gini antes y después del predial. El índice de Gini es un indicador de la concentración del ingreso y toma valores entre 0 (máxima igualdad) y 1 (máxima desigualdad). 
- Índice de Kakwani. Este indicador permite señalar la progresividad o regresividad de determinado impuesto. Se calcula de la siguiente forma:

$$
\left.K=\text { Cuasi Gini }(t)^{8}-\text { Gini (ingreso antes } t\right)
$$

Donde $t$ es el impuesto en discusión. Si K $>0$, entonces el impuesto es potencialmente progresivo y puede contribuir a disminuir la concentración del ingreso. De forma contraria, si $\mathrm{K}<0$ el impuesto será regresivo.

- Índice de Reynolds-Smolensky. Éste es un indicador global de la capacidad contributiva del impuesto. Su definición algebraica es la siguiente:

$$
R S=\operatorname{Gini}(\text { antes de } t)-G i n i(\text { ingreso después de } t)
$$

Si $R S<0$, su magnitud en términos absolutos indica cuántos puntos del Gini ha aumentado la desigualdad en la distribución del ingreso como resultado de la regresividad del impuesto. Si RS $>0$, sucede lo contrario.

\section{Equidad en la capacidad generadora de ingresos entre municipios} Asimismo, esta otra característica evalúa el impacto que tiene el predial en la desigualdad territorial. Para ello se utilizarán los datos provenientes de las estadísticas de finanzas públicas estatales y municipales del INEGI. Con esto se pretende evidenciar el impacto que tiene el predial en la capacidad de generar ingresos propios de los municipios. En esta línea, los indicadores serían los siguientes:

- Gini antes y después del cobro del predial por municipios

Para medir la concentración de la recaudación del predial se utilizará:

- Porcentaje de municipios donde se concentra el 90\% de la recaudación 


\section{A NÁLISIS POR CARACTERÍSTICAS}

\subsection{EFICIENCIA}

Desde 1989 el impuesto predial ha mostrado un incremento anual promedio del $9.43 \%$ pero con una alta volatilidad (desviación estándar de 47.5\%). Comparado con las tasas de crecimiento del producto interno bruto (PIB), se pueden observar dos fenómenos importantes. En 1995, en plena crisis económica de esa década, el impuesto predial aumentó más del 160\%, mientras que la economía caía más del 5\%. Tras la crisis del 2008-2009, este comportamiento se revierte y aunado a la caída de la economía por arriba del $4 \%$ también se registra una caída en la recaudación del predial por arriba del 7\%. Esto nos permite inferir que los municipios, a través de la recaudación del predial, no han logrado mantener tasas de crecimiento en la recaudación estables en el tiempo y han respondido de distintas formas al ciclo económico.

\section{GRÁFICO 3}

EVOLUCIÓN DEL PREDIAL EN EL TIEMPO, VARIACIÓN PORCENTUAL

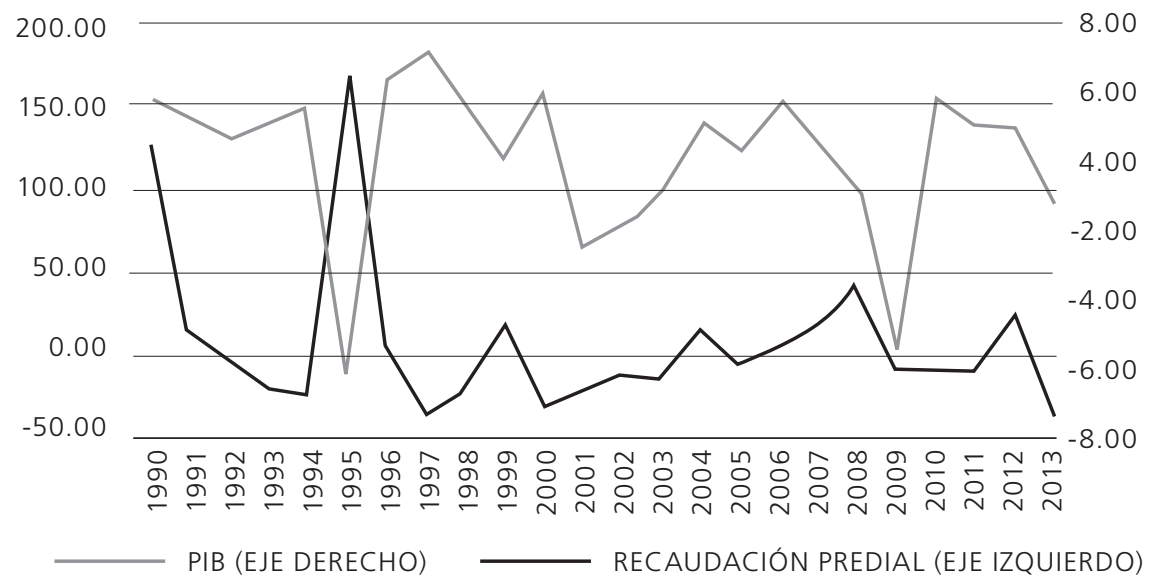

FUENTE: ELABORACIÓN PROPIA CON DATOS DEL INEGI. ESTADÍSTICAS DE FINANZAS PÚBLICAS ESTATALES Y MUNICIPALES.

A su vez, sólo el 34\% de los municipios logra recaudar por encima del $60 \%$ de la recaudación total programada. Un $66 \%$ no lo logra o ni siquiera cuenta con información sobre los predios. 
TABLA 2

EFICIENCIA EN LA RECAUDACIÓN SEGÚN EL TOTAL PROGRAMADO POR LOS MUNICIPIOS

\begin{tabular}{l|l}
$\begin{array}{c}\text { PORCENTAJE } \\
\text { PROGRAMADO }\end{array}$ & MUNICIPIOS \\
\hline 0 a 20 & $16 \%$ \\
\hline 21 a 40 & $15 \%$ \\
\hline 41 a 60 & $17 \%$ \\
\hline 61 a 80 & $17 \%$ \\
\hline 81 a 100 & $17 \%$ \\
\hline Sin información & $19 \%$ \\
\hline
\end{tabular}

FUENTE: ELABORACIÓN PROPIA CON DATOS DEL INEGI (2013).

La relación entre el impuesto predial y la oferta en el mercado hipotecario no es tan evidente. Intuitivamente al ser el impuesto predial un impuesto cuya base de cálculo es el valor de los inmuebles (terreno y construcción), se esperaría una fuerte relación con las decisiones tomadas en este mercado. Al calcular el nivel de asociación entre la recaudación del impuesto predial por habitante y la oferta de créditos hipotecarios por habitante del 2008 al 2012, se obtiene un coeficiente correlación de 0.31, lo cual muestra una relación débil entre ambas variables (ver el siguiente gráfico que evidencia esta ausencia de relación) ${ }^{9}$.

\section{GRÁFICO 4}

\section{DIAGRAMA DE DISPERSIÓN: RELACIÓN ENTRE PREDIAL Y MERCADO HIPOTECARIO}

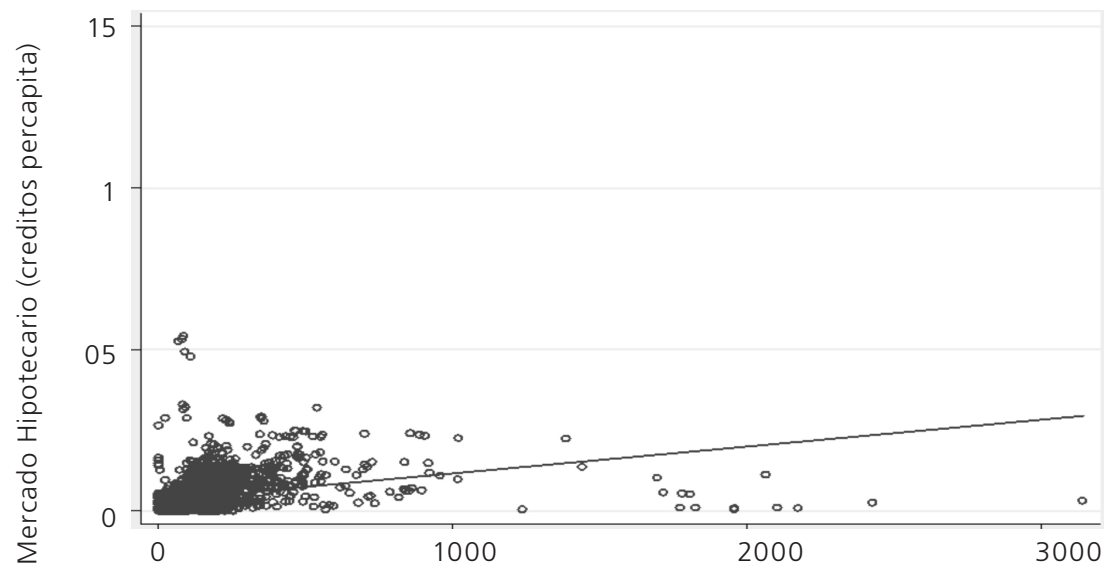


Por último, en lo que respecta al beneficio que conllevan las contribuciones del impuesto predial, existe una alta cobertura de los servicios públicos que establece la ley, pero sólo en las zonas de cabecera municipal, no así en el resto del municipio. En las cabeceras municipales existe una cobertura de servicios públicos mayor al $80 \%$, mientras que en el resto de los municipios apenas existe un $45 \%$ de cobertura promedio.

\section{TABLA3}

\section{COBERTURA DE SERVICIOS PÚBLICOS EN LOS MUNICIPIOS}

\begin{tabular}{|l|c|c|}
\hline SERVICIO PÚBLICO & CABECERA MUNICIPAL & RESTO DEL MUNICIPIO \\
\hline Agua Potable & & \\
\hline Tratamiento de aguas residuales & $86.82 \%$ & $50.05 \%$ \\
\hline Limpia y recolección de residuos sólidos & $69.56 \%$ & $29.58 \%$ \\
\hline Tratamiento y disposición de residuos & $89.73 \%$ & $51.30 \%$ \\
\hline Mercado y centrales de basto & $81.14 \%$ & $49.32 \%$ \\
\hline Panteones & $79.63 \%$ & $27.72 \%$ \\
\hline Rastros & $92.32 \%$ & $60.12 \%$ \\
\hline Áreas verdes & $84.91 \%$ & $31.56 \%$ \\
Calles y vialidades & $84.34 \%$ & $45.32 \%$ \\
\hline Espacios Públicos & $78.11 \%$ & $45.20 \%$ \\
\hline Seguridad Pública & $79.41 \%$ & $45.15 \%$ \\
\hline Tránsito & $87.96 \%$ & $58.44 \%$ \\
\hline
\end{tabular}

FUENTE: INEGI. CENSO NACIONAL DE GOBIERNOS MUNIC.IPALES Y DELEGACIONALES 2013.

\subsection{SUFICIENCIA}

La suficiencia del predial respecto al gasto público local se ha mantenido baja y estable en el tiempo. En promedio, este impuesto representa apenas el $7 \%$ del gasto. Esta cifra es considerablemente menor a la suficiencia que alcanzan las participaciones y las aportaciones, las cuales ascienden a $42 \%$ y $20 \%$ respectivamente. En cuanto al gasto corriente, la suficiencia del predial se eleva al $11 \%$, lo cual se aleja aún más de la suficiencia de las participaciones (65\%) y las aportaciones federales (33\%). Por el lado del gasto de capital, la recaudación del predial equivale a un $30 \%$ de este tipo de gasto, mientras que las participaciones alcanzan el $179 \%$ y las aportaciones un $79 \%$. En cuanto a la deuda, las tres fuentes de financiamiento rebasan el $100 \%$ del gasto en este rubro.

En los siguientes cuatro gráficos se puede observar un comportamiento similar: poca suficiencia del impuesto predial (sólo en la deuda municipal rebasa el 100\%), una considerable alza en la suficiencia de las participaciones después de 1995 y una estrepitosa caída de la misma en 2008, y una tendencia gradual del aumento en la suficiencia de las aportaciones. 


\section{GRÁFICO 5 \\ SUFICIENCIA DEL PREDIAL, LAS PARTICIPACIONES Y LAS APORTACIONES RESPECTO AL GASTO PÚBLICO LOCAL}

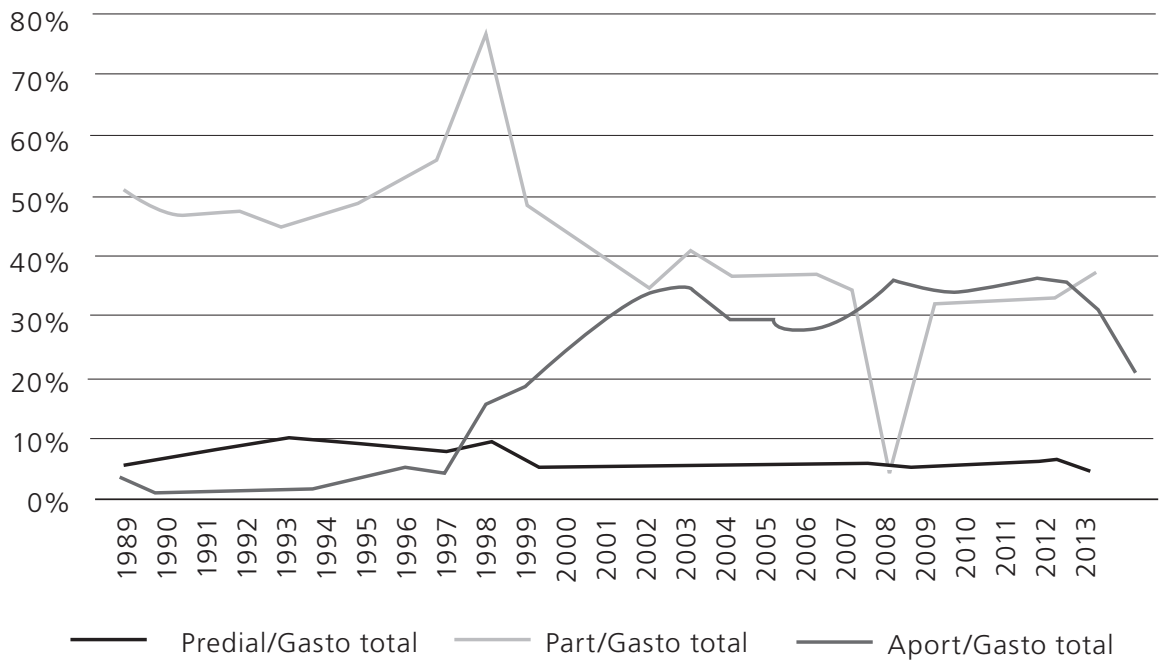

FUENTE: ELABORACIÓN PROPIA CON DATOS DEL INEGI.

\section{GRÁFICO 6 \\ SUFICIENCIA DEL PREDIAL, LAS PARTICIPACIONES Y LAS APORTACIONES RESPECTO AL GASTO CORRIENTE}

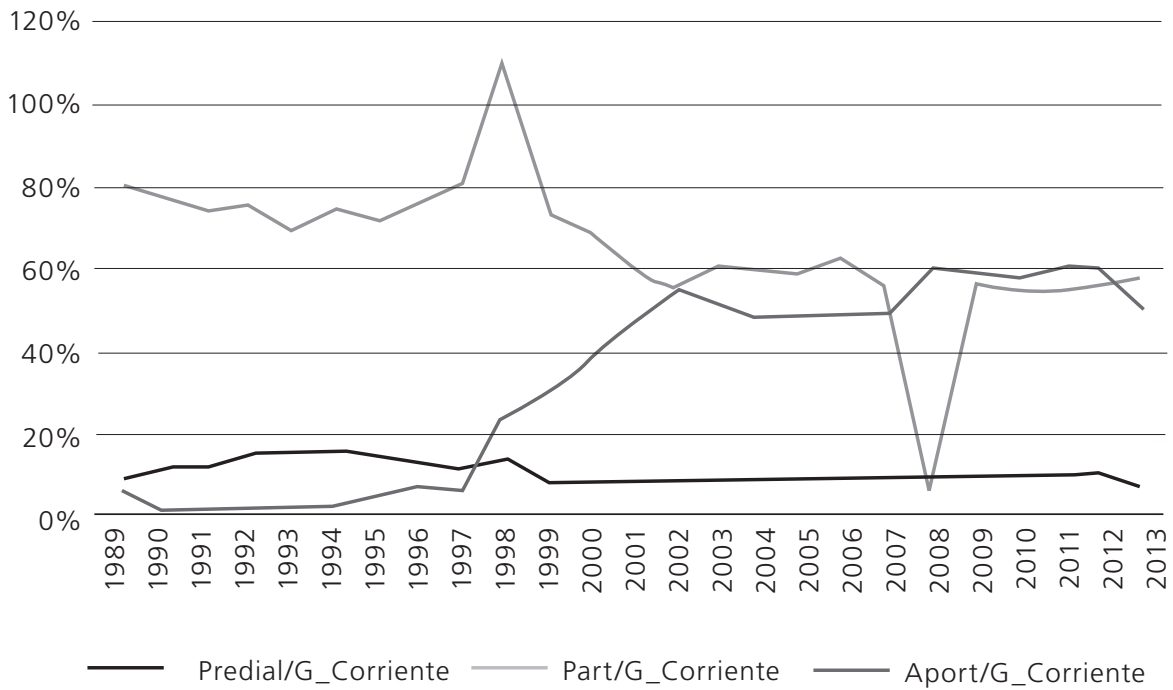




\section{GRÁFICO 7}

SUFICIENCIA DEL PREDIAL, LAS PARTICIPACIONES Y LAS APORTACIONES RESPECTO AL GASTO DE CAPITAL

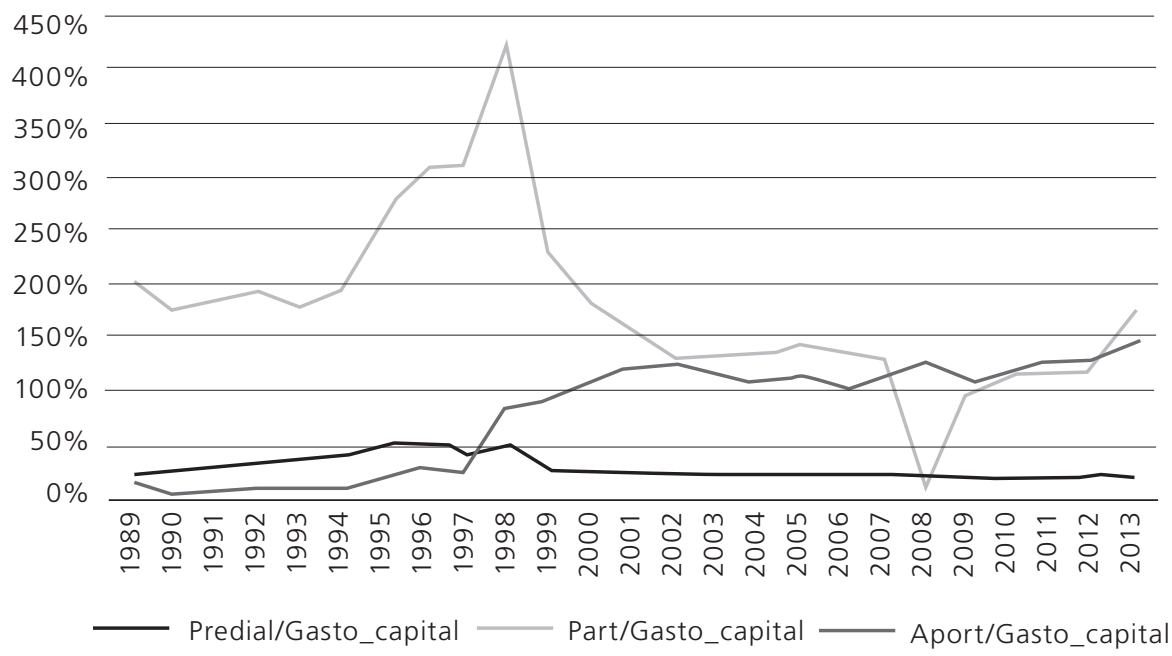

FUENTE: ELABORACIÓN PROPIA CON DATOS DEL INEGI.

\section{GRÁFICO 8}

SUFICIENCIA DEL PREDIAL, LAS PARTICIPACIONES Y LAS APORTACIONES RESPECTO AL GASTO POR PAGO DE SERVICIOS DE LA DEUDA PÚBLICA EN LOS MUNICIPIOS

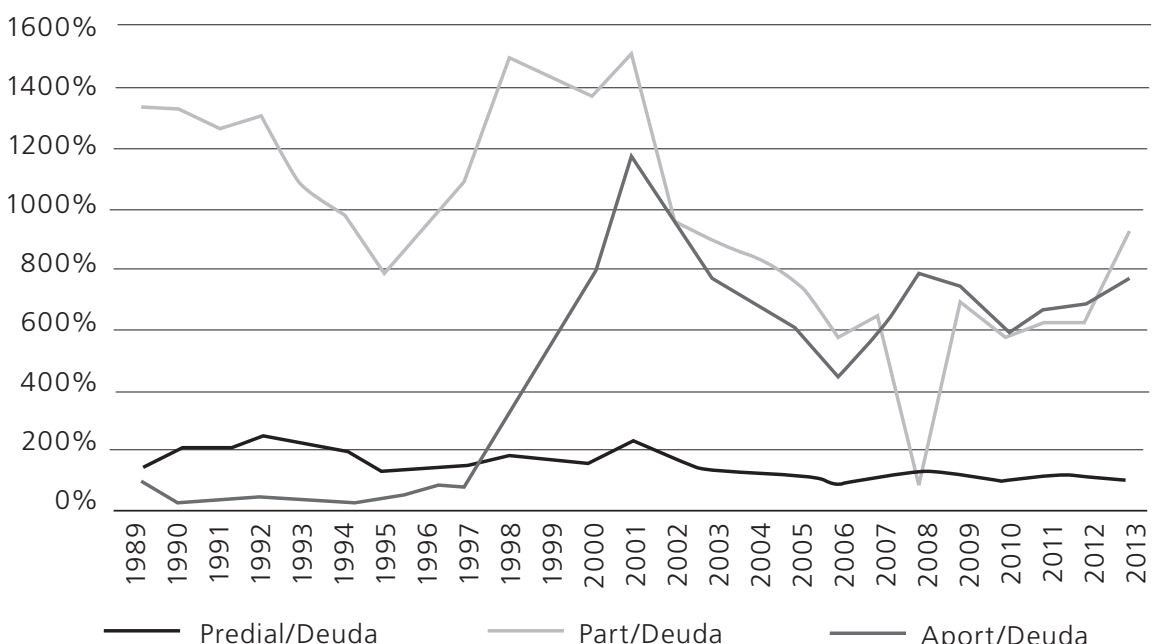

FUENTE: ELABORACIÓN PROPIA CON DATOS DEL INEGI. 


\subsection{SIMPLICIDAD ADMINISTRATIVA}

Como ya se señaló en párrafos anteriores, la administración del impuesto a la propiedad requiere de instrumentos rigurosos y metodologías sistemáticas para actividades clave como la actualización y el mantenimiento del catastro, y la valuación de las propiedades. Éstas son tareas que en primera instancia requieren de información catastral sobre los predios. En esto pareciera que en México no existiese una restricción administrativa. El 90\% de los municipios cuenta con información sobre los predios.

TABLA 4

ADMINISTRACIONES PÚBLICAS MUNICIPALES CON INFORMACIÓN DE CATASTRO SEGÚN LA AUTORIDAD ENCARGADA DE LA RECAUDACIÓN DEL IMPUESTO PREDIAL

\begin{tabular}{l|r|r}
\multicolumn{1}{c|}{ AUTORIDAD } & MUNICIPIOS & $\%$ \\
\hline Gobierno municipal & 2053 & 84 \\
\hline Gobierno del estado & 133 & 5 \\
\hline Otro & 25 & 1 \\
\hline En el municipio no se cobra el impuesto predial & 159 & 7 \\
\hline No se sabe & 23 & 1 \\
\hline No disponible & 48 & $\mathbf{1 0 0}$
\end{tabular}

FUENTE: INEGI CENSO NACIONAL DE GOBIERNOS MUNICIPALES Y DELEGACIONALES 2013.

TABLA 5

MUNICIPIOS CON INFORMACIÓN CATASTRAL POR PERIODO DE ACTUALIZACIÓN

\begin{tabular}{|l|c|c|}
\hline PERIODO DE ACTUALIZACIÓN CATASTRAL & MUNICIPIOS & $\%$ \\
\hline 2013 & 578 & 24 \\
2012 & 544 & 22 \\
2011 & 124 & 5 \\
2011 & 282 & 12 \\
No se ha realizado actualización & 577 & 24 \\
No se sabe & 288 & 12 \\
No disponible & 48 & 2 \\
TOTAL & $\mathbf{2 4 4 1}$ & $\mathbf{1 0 0}$ \\
\hline
\end{tabular}

FUENTE: INEGI. CENSO NACIONAL DE GOBIERNOS MUNICIPALES Y DELEGACIONALES 2013 
No obstante a lo anterior, actualizar la información catastral anualmente no es una tarea que todos los municipios puedan realizar con facilidad. De los municipios que declararon tener información catastral, sólo 578 actualizaron sus catastros el 2013, 544 lo hicieron el 2012, 124 el 2011, 282 antes del 2011, 577 no la han actualizado, 288 declararon no saber y 48 no cuentan con la información. Con esto podemos concluir que al 2013, el 76\% de los municipios no cuenta con información catastral actualizada.

Otra dificultad es la actualización de valores catastrales en conformidad a los valores del mercado. Al 2013 sólo 491 municipios contaban con valores catastrales actualizados, 588 lo tenían al 2012, 136 al 2011 y 264 tenían información posterior al 2011. Los 962 municipios restantes que declararon tener información catastral de alguna $\mathrm{u}$ otra forma no cuentan con los valores catastrales (o la información) actualizados. Tomando a los municipios que actualizaron sus valores a partir del 2011, podemos concluir que el 50\% de los municipios no cuenta con valores catastrales actualizados conforme a valores de mercado.

TABLA 6

\section{ACTUALIZACIÓN DE VALORES CATASTRALES CONFORME A LOS VALORES DE MERCADO}

\begin{tabular}{|l|r|r|}
\hline PERIODO DE ACTUALIZACIÓN DE VALORES & MUNICIPIOS & $\%$ \\
\hline CATASTRALES & & 20 \\
2012 & 491 & 24 \\
2011 & 588 & 6 \\
Antes de 2011 & 136 & 11 \\
No se ha realizado actualización & 264 & 22 \\
No se sabe & 534 & 16 \\
No disponible & 380 & 2 \\
TOTAL & 48 & $\mathbf{1 0 0}$ \\
\hline
\end{tabular}

FUENTE: INEGI. CENSO NACIONAL DE GOBIERNOS MUNICIPALES Y DELEGACIONES 2013.

Por último, es importante destacar que apenas el 19\% del total de municipios $(2,441)$, de alguna o de otra forma han emprendido acciones de modernización catastral.

\subsection{TRANSPARENCIA}

Según el índice de transparencia presupuestaria explicado en el apartado anterior, los municipios presentan bajos niveles de transparencia sobre el uso de los recursos públicos. Así, del 0 al 100, el índice promedio en 2008 
TABLA 7

ACCIONES DE MODERNIZACIÓN CATASTRAL

\begin{tabular}{l|c|c}
\multicolumn{1}{c|}{ MODERNIZACIÓN } & MUNICIPIOS & $\%$ \\
\hline $\begin{array}{l}\text { Administraciones públicas municipales con acciones } \\
\text { de modernización catastral }\end{array}$ & 475 & $19 \%$ \\
\hline Actualizar el padrón catastral & 368 & $15 \%$ \\
\hline Generar o actualizar la cartografía catastral & 250 & $10 \%$ \\
\hline Adquirir un sistema de gestión catastral & 121 & $5 \%$ \\
\hline Adquirir equipamiento e infraestructura & 158 & $6 \%$ \\
\hline Adecuar los espacios físicos & 65 & $3 \%$ \\
\hline Mejoramiento de procesos catastrales & 177 & $7 \%$ \\
\hline Otro & 13 & $1 \%$ \\
\hline Sin identificar & 38 & $2 \%$ \\
\hline
\end{tabular}

FUENTE: INEGI. CENSO NACIONAL DE GOBIERNOS MUNICIPALES Y DELEGACIONES 2013.

TABLA 8

ÍNDICE DE INFORMACIÓN PRESUPUESTAL, PERIODO 2008-2012

\begin{tabular}{|l|l|c|c|c|c|}
\hline AÑO & PROMEDIO & $\begin{array}{c}\text { DESVIACIÓN } \\
\text { ESTÁNDAR }\end{array}$ & $\begin{array}{c}\text { ÍNDICE } \\
\text { MINIMO }\end{array}$ & $\begin{array}{c}\text { ÍNDICE } \\
\text { MAXIMO }\end{array}$ & $\begin{array}{c}\text { MUNICIPIOS } \\
\text { ANALIZADOS }\end{array}$ \\
\hline 2008 & 6.66 & 13.23 & 0 & 58 & 391 \\
\hline 2009 & 6.66 & 13.23 & 0 & 58 & 391 \\
\hline 2010 & 10.11 & 17.07 & 0 & 97 & 390 \\
\hline 2011 & 10.06 & 14.53 & 0 & 100 & 390 \\
\hline 2012 & 15.09 & 14.09 & 0 & 100 & 390 \\
\hline
\end{tabular}

ELABORACIÓN PROPIA CON DATOS DEL IMCO.

TABLA 9

ÍNDICE DE INFORMACIÓN PRESUPUESTAL: MUNICIPIOS CON ÍNDICES POR ARRIBA DE 50, PERIODO 2008 -2012

\begin{tabular}{|c|c|c} 
AÑO & $\begin{array}{c}\text { MUNICIPIOS C } \\
\text { ON INDICE }>\text { 50 }\end{array}$ & $\begin{array}{c}\text { MUNICIPIOS } \\
\text { CON INDICE }=100\end{array}$ \\
\hline 2008 & 4 & 0 \\
\hline 2009 & 4 & 0 \\
\hline 2010 & 20 & 0 \\
\hline 2011 & 7 & 1 \\
\hline 2012 & 9 & 2 \\
\hline TOTAL & $\mathbf{4 4}$ & $\mathbf{3}$ \\
\hline
\end{tabular}

ELABORACIÓN PROPIA CON IJATOS DEL IMCO. 
fue de 6.66 aumentando en más de 7 puntos para el 2012. Aunado a esto, y tal como se muestra en la siguiente tabla, es importante destacar que existen altos niveles de dispersión respecto a este índice. Asimismo, existen municipios que sí alcanzan el índice máximo (100) y municipios donde simplemente no existe transparencia presupuestal (índice igual a 0).

Ahora bien, son pocos los municipios que alcanzan índices mínimamente aceptables, como sería arriba de 50. Del 2008 al 2012, se observa que sólo 44 municipios lo lograron. Más considerable aún, es que de éstos solo tres lograron el nivel más alto del índice.

A expensas de que en futuras investigaciones se profundice esta característica, estos datos nos revelan que prácticamente no existen condiciones de responsabilidad política para el manejo de los recursos públicos, dentro de los que se encuentran los provenientes de la recaudación del predial.

TABLA 10

\section{PAGO DE LOS HOGARES DEL IMPUESTO PREDIAL: DISTRIBUCIÓN Y TASAS MEDIAS}

\begin{tabular}{ccc} 
DECIL DE INGRESO & $\begin{array}{c}\text { DISTRIBUCIÓN DEL PAGO DE } \\
\text { PREDIAL }\end{array}$ & $\begin{array}{c}\text { PROGRESIÓN DE } \\
\text { TASAS MEDIAS }\end{array}$ \\
\hline 1 & $0.5 \%$ & $0.10 \%$ \\
2 & $26.6 \%$ & $2.28 \%$ \\
3 & $2.0 \%$ & $0.17 \%$ \\
4 & $0.4 \%$ & $0.05 \%$ \\
5 & $4.8 \%$ & $0.22 \%$ \\
6 & $2.0 \%$ & $0.08 \%$ \\
7 & $8.3 \%$ & $0.22 \%$ \\
8 & $14.3 \%$ & $0.47 \%$ \\
9 & $2.7 \%$ & $0.07 \%$ \\
10 & $38.5 \%$ & $0.18 \%$ \\
\hline
\end{tabular}

ELABORACIÓN PROPIA A PARTIR DE ENIGH (2012).

\subsection{JUSTICIA}

\section{Equidad en la distribución de ingresos}

En lo que respecta al pago del predial, la progresividad del predial en México pareciera que no es tan evidente. Tal como se señala en el apartado anterior, se utilizó la Encuesta Nacional de Ingresos y Gastos de los Hogares (2012) para analizar el pago de predial que se realiza dentro del gasto de los hogares. Al agrupar por deciles de ingreso per cápita de los hogares, si bien el 38\% del gasto total en pago del predial se concentra en el decil 10, un $27 \%$ 
se concentra en el segundo decil. Asimismo, al estimar las tasas medias, se encuentra que los hogares ubicados en el primer decil de ingresos per cápi-

TABLA 11

IMPACTO REDISTRIBUTIVO DEL PREDIAL

\begin{tabular}{l|c}
\multicolumn{1}{c|}{ INDICADOR } & ESTIMACIÓN \\
& \\
Gini previo a predial & 0.52 \\
\hline Cuasi-Gini predial & 0.88 \\
\hline Kakwani & 0.36 \\
\hline Gini posterior al pago de predial & 0.52 \\
\hline Reynolds Smolensky & -0.001
\end{tabular}

ELABORACIÓN PROPIA A PARTIR DE ENIGH (2J12)

ta destinan el $0.10 \%$ de su renta al pago del predial y los hogares ubicados en el último decil destinan el $0.18 \%$; no obstante, de igual forma la tasa más alta se encuentra en el segundo decil, donde se destina el $2.28 \%$.

Así pues, al estimar el coeficiente de Gini de los ingresos corrientes de los hogares antes y después del pago del predial, se observa un nulo impacto

TABLA 12

\section{GINI ANTES Y DESPUÉS DE LA RECAUDACIÓN DEL PREDIAL}

\begin{tabular}{c|c|c}
\hline AÑO & $\begin{array}{c}\text { ANTES: INGRESOS } \\
\text { PROPIOS MENOS } \\
\text { PREDIAL }\end{array}$ & $\begin{array}{c}\text { DESPUÉS: INGRESOS } \\
\text { PROPIOS }\end{array}$ \\
\hline 2008 & 0.49 & 0.69 \\
\hline 2009 & 0.49 & 0.68 \\
\hline 2010 & 0.47 & 0.71 \\
\hline 2011 & 0.48 & 0.71 \\
\hline 2012 & 0.47 & 0.72 \\
\hline
\end{tabular}

ELABORACIÓN PROPIA CON JATOS DEL INEGI E IMCO ${ }^{10}$.

redistributivo; incluso, el cálculo del índice de Reynolds-Smolensky, permite inferir que el predial aumenta en 0.001 puntos del Gini la desigualdad de ingresos.

Por otro lado, el resultado positivo del índice de Kakwani (0.36), permite anticipar que el impuesto predial tiene un fuerte potencial de progresividad.

10. El análisis se hizo considerando la recaudación del predial y los ingresos propios municipales en pesos del 2012. 


\section{GRÁFICO 9}

EVOLUCIÓN DEL PORCENTAJE DE MUNICIPIOS QUE CONCENTRAN EL 90\% DE LA RECAUDACIÓN DEL PREDIAL, 1990-2013

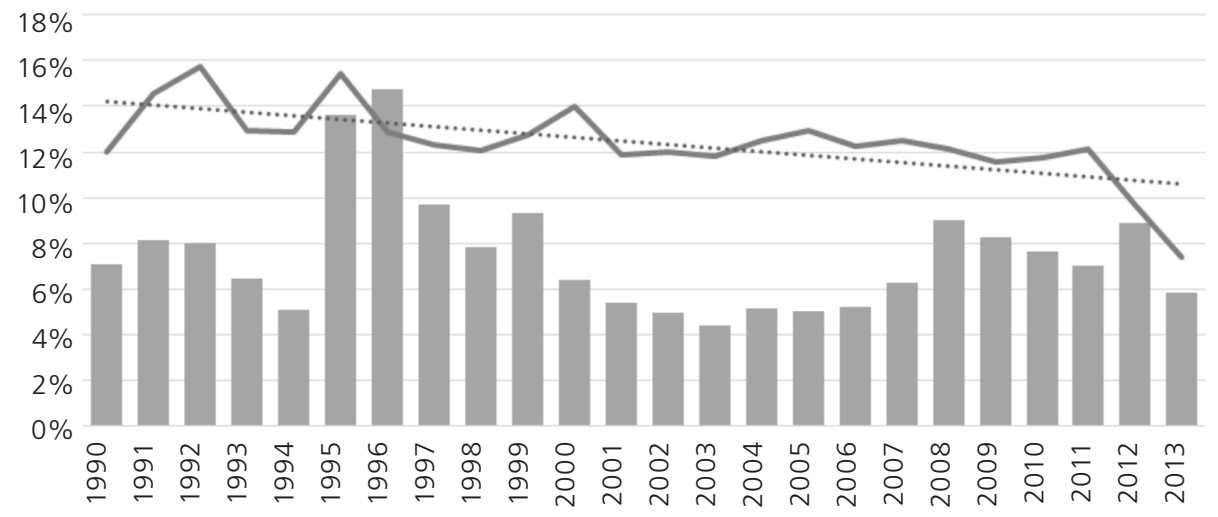

Recaudación del predial (millones de dólares aprecios constantes, eje derecho)

Porcentaje de municipios que concentran el 90\% de la recaudación (eje izquierdo)

Lineal (Porcentaje de municipios que concentran el 90\% de la recaudación (eje izquierdo))

ELABORACIÓN PROPIA CON DATOS DEL INEGI. ESTADÍSTICAS DE LAS FINANZAS PÚBLICAS ESTATALES Y MUNICIPALES.

Los resultados de este índice deben tomarse con cautela debido a que este índice no está influenciado por su recaudación y por ende dice poco acerca de su capacidad redistributiva.

\section{Equidad en la capacidad generadora de ingresos entre municipios}

Con el fin de evaluar la capacidad de generar ingresos en los municipios de México, se estimó el coeficiente de Gini de los ingresos propios municipales antes y después de la recaudación del predial. Tal como se intuía, se encontraron indicios de que con el cobro de este impuesto se exacerba considerablemente la desigualdad territorial.

Por último, al analizar la distribución porcentual de la recaudación de 1990 al 2013, observamos que el $90 \%$ del total de lo recaudado por impuesto predial se concentra sólo en el $12 \%$ de los municipios. La tendencia muestra una baja gradual en el porcentaje de municipios que concentran el $90 \%$ de la recaudación del predial. Por ejemplo, para el 2013 la concentración del 90\% quedó sólo en el $7 \%$ del total los municipios. 


\section{C O N C L U S I O N S}

El impuesto predial es el impuesto municipal más importante en México. Su participación por arriba del 50\% de los ingresos tributarios nos permite afirmar lo anterior. Por otro lado, pareciera que también es el principal instrumento para gravar la riqueza y el patrimonio de las personas. Con todo, el predial es un impuesto importante que debiese sujetarse a análisis y decisiones de política de mayor trascendencia.

En resumen, de acuerdo con la radiografía realizada, el predial es un impuesto que revela la falta de capacidad fiscal y de competencias tributarias en los municipios de México. No obstante, pareciera no tener una relación evidente con las decisiones económicas en los municipios. Comparado con las transferencias del gobierno federal, el predial evidencia los altos niveles de dependencia que los municipios han adquirido para dar suficiencia al gasto público local. Las tareas de actualización y modernización catastral se cumplen en muy pocos municipios, lo cual evidentemente va en detrimento de la recaudación del predial en la mayoría de los municipios. Con los resultados también se encuentra que las condiciones de responsabilidad política no son las adecuadas, ya que muy pocos municipios logran transparentar claramente la información sobre el manejo de sus recursos públicos. Por último, al analizar las contribuciones, el impuesto predial pareciera regresivo; asimismo, en cuanto a las desigualdades territoriales en materia de generación de recursos propios, el cobro del predial muestra indicios de exacerbarlas (ver cuadro-resumen de la radiografía en el anexo). Por último, de este análisis se desprenden algunos desafíos:

- Existe un potencial recaudatorio. Se deben hacer esfuerzos en las tres instancias de gobierno por adoptar medidas que compensen las debilidades institucionales y de gestión entre municipios, de forma tal alcanzar mayores y más estables niveles de recaudación.

- Es necesario profundizar el análisis sobre la incidencia del predial en las decisiones económicas, como por ejemplo el cambio de precios en terrenos y construcciones, así como en la inversión local.

- Los municipios deben legitimar la recaudación del predial logrando una mayor cobertura en los servicios públicos en todas las zonas de los municipios, no sólo en las cabeceras.

- Reducir la dependencia. Se deben discutir mecanismos que reduzcan la suficiencia de los recursos del gobierno federal sobre el gasto 
público local, de manera tal que esta disminución sea compensada con un aumento en los recursos propios de los municipios, sobre todo los provenientes del predial.

- Las tres instancias de gobierno deben asumir una agenda común sobre las tareas catastrales, de forma tal de lograr una homogeneidad en la información y la actualización en los valores catastrales de todos los predios.

- Las legislaturas locales debiesen fortalecer los parámetros en la aprobación de las leyes de ingreso de los municipios y propiciar un cambio institucional en el manejo y la rendición de cuentas de los recursos públicos locales.

- Aumentar el potencial redistributivo del predial. Recientemente la literatura relacionada a medir la concentración del ingreso y la riqueza ha señalado que fortalecer impuestos como el predial, que gravan directamente la riqueza, podrían contribuir a reducir los niveles de desigualdad en dos sentidos: que contribuyan en mayor medida aquellos individuos y familias con mayor capacidad para hacerlo, y a través de la obtención de registros tributarios que permitan obtener mediciones más reales sobre la desigualdad. 


\section{B I B L I O G R A F Í A}

Aguilar, Genaro (2010). Capacidad tributaria y finanzas públicas metropolitanas en México. Estudios Demográficos y Urbanos, No. 25, pp. 103-132.

Amarante, Verónica y Jiménez, Juan Pablo (2015). Desigualdad, concentración y rentas altas en América Latina, en Juan Pablo Jiménez (ed.), Desigualdad, concentración del ingreso y tributación sobre las altas rentas en América Latina, Libros de la CEPAL, Nº 134 (LC/G.2638-P), Santiago de Chile, Comisión Económica para América Latina y el Caribe (CEPAL).

Bahl, R. (2009). Fixing the Property and Land Tax Regime in Developing Countries. Atlanta, GA: The Andrew Young School of Policy Studies, Georgia States University.

Bahl, R., J. Martínez-Vazquez and J. M. Youngman. (2010). Whither the Property Tax: New Perspsectives on a Fiscal Mainstay. En: R. Bahl, J. Martínez-Vázquez y J. M. Youngman, "Challenging the Conventional Wisdom on the Property Tax" (pp. 3-14). Cambridge, MA: Lincoln Institute of Land Policy.

Besley, T. y H. Rosen. (1998). Vertical Externalities in Tax Setting: Evidence from Gasoline and Cigarettes. Journal of Public Economics, No.70, pp.383-398.

Bird, Richard (2002). Intergovernmental fiscal relations in Latin America: Policy design and policy outcomes. Inter-American Development Bank, Sustainable Development Department, Washington, D.C.

Bonet, Jaime, Múñoz, Andrés y Pineda Manheim, Carlos (2014). Introducción en Bonet, Jaime, Múñoz, Jaime y Pineda Manheim, Carlos (ed.) "El potencial oculto. Factores determinants y oportunidades del impuesto a la propiedad inmobiliaria en América Latina". Banco Interamericano de Desarrollo.

Bonet, Jaime y Rueda, Fabio (2011). Esfuerzo fiscal en los estados mexicanos. Documento de trabajo, Banco Interamericano de Desarrollo, Washington.

Broid Krauze, Daniel (2010), “La evolución predial en México: los incentivos cruzados de la descentralización fiscal y política", Centro de Estudios de las Finanzas Públicas, LXI Legislatura, Cámara de Diputados, Vol. 2, Núm. 3-4.

Cabrero, Enrique (2010). Gobierno y política local en México: luces y sombras de las reformas descentralizadoras. Revista Política y Sociedad, No. 47, pp. 47-61.

(2004). Capacidades institucionales en gobiernos subnacionales de México ¿Un obstáculo para la descentralización fiscal? Revista Gestión y Política Pública, Vol. 13, No. 3, Centro de Investigación y Docencias Económicas (CIDE), México, DF.

Chávez Maza, Luis Agusto (2014). Desistimiento fiscal, incertidumbre y propiedad social en los municipios de México. Revista Región y Sociedad, No. 61, pp. 87-117. 
Chawla, Raj y Wannel, Ted, (2003). Property taxes. Perspectives on labor and income, Vol. 4 No. 7.

Consejo Nacional de Armonización Contable (2010). Clasificador por tipo de gasto. Acuerdo rescatado de: www.conac.gob.mx

Constitución Política de los Estados Unidos Mexicanos. Texto vigente DOF 07/07/2014. Diario Oficial de la Federación 1917.

Fischell, William. (2001), Homevoters, Municipal Corporate Governance, and the benefit view of the Property tax. National Tax Journal, Vol.54, No.1.

Fischel, W., W. Oates y J. Youngman, J. (2011). Are Local Property Taxes Regressive, Progressive, or What? Documento de trabajo presentado en el Congreso Anual del International Institute of Public Finance.

Gámez, Cesáreo e Ibarra, Alejandro (2009). El ciclo politico y oportunista y el gasto de los estados mexicanos. Gestión y Política Pública, No. 18, pp. 39-65

Hamilton, Bruce. (1976), The Effects of Property Taxes and Local Public Spending on Property Values, A Theoretical Comment. Journal of Political Economy, Vol. 84, No. 3.

Ibarra, Jorge (2013). Entorno político y dependencia financiera de los estados mexicanos. Gestión y Política Pública XXII, pp. 3-44.

IMCO (2014). ¿Quién manda aquí? La gobernanza de las ciudades y el territorio en México. IMCO.

INEGI (2013). Censo Nacional de Gobiernos Municipales y Delegacionales.

(2012). Encuesta de Ingresos y Gastos de los Hogares (ENIGH).

Jorrat, Michael (2009). La Tributación directa en Chile: equidad y desafíos. División de Desarrollo Económico de la Comisión Económica para América Latina y el Caribe (CEPAL).

Keen, M. (1998). Vertical Tax Externalities in the Theory of Fiscal Federalism. IMF Staff Papers Núm. 45, pp. 454-485. Washington, D.C., FMI.

Moreno Jaimes, Carlos (2007). Gasto público y elecciones: una explicación política de la asignación de los presupuestos municipales en México. Foro Internacional No. 47, pp. 408-434.

Musgrave, P. (1992). Hacienda Pública Teórica y Aplicada. Ed. Mc Graw-Hill.

Norregaard, J. (2013). Taxing Immovable Property, Revenue Potential and Implementation Challenges. Working Paper. Washington, D.C, FMI.

Oates, W. (1969). The effect of property taxes and local public spending on property 
values: an empirical study of tax capitalization and the Tiebout hypothesis, Journal of Political Economy, Vol. 77, pp. 957-971.

Olson, Mancur. (1969). The Principle of Fiscal Equivalence: The Division of Responsibilities among Different Levels of Government. American Economic Review 59(2), pp. $479-87$.

Ramírez, Roberto y Erquizio, Espinal (2011). Capacidad y esfuerzo fiscal en las entidades federativas en México: medición y determinantes. Paradigma económico No. 3, pp. 37-70.

Sánchez Daza, Germán y Pérez Juárez, Nayeli (2009). Empelo y crisis del patrón neoliberal en las entidades del país. El Cotidiano, No. 157, pp. 670-687.

Sennoga, Edward, Sjoquist, Davis y Wallace, Rally, (2007), Incidence and Economic Impacts of property taxes in developing and transitional countries. Working Paper 07-36. Andrew School of Policy Studies, GSU.

Sepúlveda, Cristian and Martínez-Vázquez, Jorge (2011). Explaining Property Tax Collections in Developing Countries: The case of Latin American. International Studies Program, Working Paper 11-09.

Simon, H. (1943). The incidence of a Tax on Urban Real Property. The Quarterly Journal of Economics, Vol. 57. No. 3, pp. 398-420.

Slack, E. (2010). The Property Tax...in Theory and Practice. Documento de trabajo Núm. 02. Toronto, Canada: Institute on Municipal Finance and Governance, Munk School of Global Affairs.

Sour, Laura (2008). Un repaso sobre los conceptos sobre capacidad y esfuerzo fiscal, y su aplicación en los gobiernos locales mexicanos. Estudios Demográficos y Urbanos, No. 23, pp. 271-297.

Stiglitz, Joseph (2003). La economía del sector público. $3^{\text {a }}$ Ed. Antoni Bosch editor.

Stuart Mill, John (1848). Principios de Economía Política. Fondo de Cultura Económica, México D.F. (2006).

Tiebout, C. (1956). A Pure Theory of Local Expenditures. The Journal of Political Economy, Vol. 64, pp. 416-424.

Weingast, Barry (2008). Second Generation Fiscal Federalism: The Implications of fiscal incentives. Journal Of Urban Economics, doi:10.1016/j.jue.2008.12.005. 


\section{A NEXOS}

\section{GRÁFICO 10}

RECAUDACIÓN DEL IMPUESTO A LA PROPIEDAD INMOBILIARIA (COMO PORCENTAJE DEL PIB) Y RATIOS ENTRE LO QUE SE RECAUDA EN OTROS PAÍSES Y LO QUE SE RECAUDA EN MÉXICO

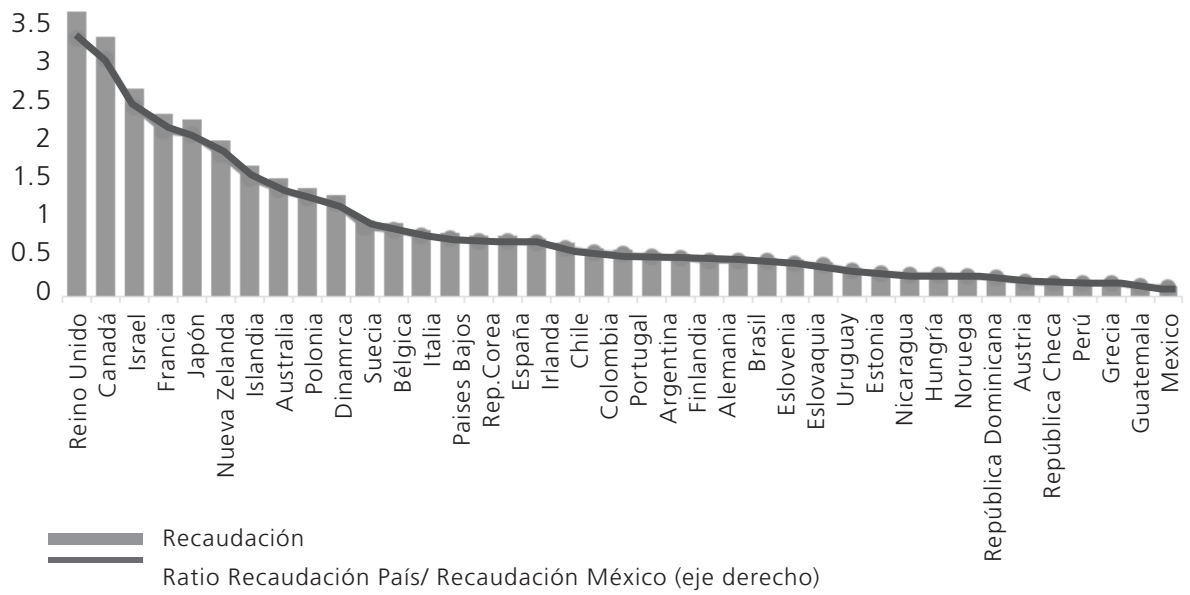

FUENTE: ELABORACIÓN PROPIA CON BASE EN BONET, MUÑOZ Y MANNHEIM, 2014.

\section{GRÁFICO 11}

RECAUDACIÓN DEL IMPUESTO A LA PROPIEDAD INMOBILIARIA (COMO PORCENTAJE DEL PIB) Y RATIOS ENTRE LO QUE SE RECAUDA EN PAÍSES DE AMÉRICA LATINA Y LO QUE SE RECAUDA EN MÉXICO

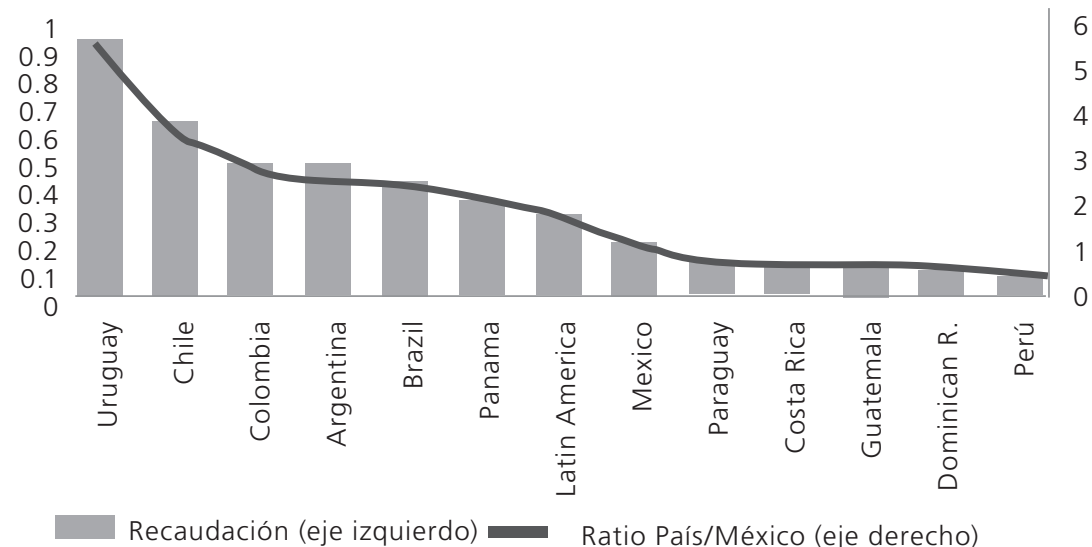


TABLA 13

CUADRO-RESUMEN: RADIOGRAFÍA DEL PREDIAL

\begin{tabular}{|c|c|c|}
\hline CARACTERÍSTICA & INDICADOR & RESULTADOS \\
\hline \multirow{4}{*}{ EFICIENCIA } & Tasa de crecimiento, 1989-2013 & $\begin{array}{l}9.43 \text { con altos niveles de dispersión } \\
\text { (d.e. } 47.5 \text { ) }\end{array}$ \\
\hline & $\begin{array}{l}\text { Recaudación efectiva del predial } \\
\text { respecto al total programado }\end{array}$ & $\begin{array}{l}\text { Sólo el } 34 \% \text { de los municipios logra } \\
\text { recaudar por arriba del } 60 \% \text { del } \\
\text { total programado }\end{array}$ \\
\hline & $\begin{array}{l}\text { Correlación entre la recaudación } \\
\text { del predial y el mercado } \\
\text { hipotecario }\end{array}$ & $\begin{array}{l}\text { Un coeficiente de } 0.31 \text {, lo cual } \\
\text { denota una débil relación en las } \\
\text { decisiones económicas }\end{array}$ \\
\hline & Cobertura de servicios públicos & $\begin{array}{l}\text { Las zonas que están fuera de las } \\
\text { cabeceras municipales apenas } \\
\text { alcanzan el } 45 \% \text { de cobertura de } \\
\text { servicios públicos }\end{array}$ \\
\hline \multirow{4}{*}{ SUFICIENCIA } & $\begin{array}{l}\text { Recaudación respecto al gasto } \\
\text { total }\end{array}$ & $\begin{array}{l}\text { Un } 7 \% \text { de suficiencia, muy por } \\
\text { debajo de la suficiencia de las } \\
\text { participaciones y aportaciones } \\
\text { federales }\end{array}$ \\
\hline & $\begin{array}{l}\text { Recaudación respecto al gasto } \\
\text { corriente }\end{array}$ & $\begin{array}{l}\text { Un } 11 \% \text { de suficiencia, de igual } \\
\text { forma muy por debajo de las } \\
\text { participaciones y aportaciones } \\
\text { federales }\end{array}$ \\
\hline & $\begin{array}{l}\text { Recaudación respecto al gasto } \\
\text { de capital }\end{array}$ & $\begin{array}{l}\text { Un } 30 \% \text {, mientras que las } \\
\text { participaciones y transferencias } \\
\text { rebasan el } 100 \% \text { de suficiencia }\end{array}$ \\
\hline & $\begin{array}{l}\text { Recaudación respecto al gasto } \\
\text { en pago de servicios de la deuda } \\
\text { pública }\end{array}$ & Suficiente \\
\hline \multirow{4}{*}{ SIMPLICIDAD } & $\begin{array}{l}\text { Municipios con información } \\
\text { catastral }\end{array}$ & $90 \%$ \\
\hline & $\begin{array}{l}\text { Municipios con información } \\
\text { catastral actualizada }\end{array}$ & $24 \%$ \\
\hline & $\begin{array}{l}\text { Municipios con valores } \\
\text { catastrales actualiazados } \\
\text { conforme a valores de mercado }\end{array}$ & $50 \%$ \\
\hline & $\begin{array}{l}\text { Municipios con acciones de } \\
\text { modernización catastral }\end{array}$ & $19 \%$ \\
\hline
\end{tabular}




\begin{tabular}{|c|c|c|}
\hline CARACTERÍSTICA & INDICADOR & RESULTADOS \\
\hline \multirow{2}{*}{$\begin{array}{l}\text { RESPON- } \\
\text { SABILIDAD } \\
\text { POLÍTICA }\end{array}$} & $\begin{array}{l}\text { Índice de transparencia } \\
\text { presupuestaria (0 a 100) }\end{array}$ & $\begin{array}{l}\text { Alcanzan un } 9.7 \text { promedio con una } \\
\text { alta dispersión (14.43) , 2008-2012 }\end{array}$ \\
\hline & $\begin{array}{l}\text { Municipios con índices mayores a } \\
50 \text { e igual a } 100\end{array}$ & 44 y 3 respectivamente, 2008-2012 \\
\hline \multirow{6}{*}{ JUSTICIA } & $\begin{array}{l}\text { Distribución del 100\% del pago } \\
\text { del predial }\end{array}$ & $\begin{array}{l}\text { El pago del predial no resulta } \\
\text { progresivo. La mayor parte del } \\
\text { pago se encuentran en el decil } 2 \\
(26.6 \%) \text { y el decil } 10(38.5 \%)\end{array}$ \\
\hline & Tasas medias & $\begin{array}{l}\text { La mayor parte de la renta que se } \\
\text { destinada al pago del predial se } \\
\text { encuentra en el decil } 2 \text { ( } 2.28 \% \text { del } \\
\text { total de la renta) }\end{array}$ \\
\hline & Índice Reynolds-Smolensky & $\begin{array}{l}\text { Las contribuciones del predial } \\
\text { aumentan la desigualdad, en } \\
0.001 \text { puntos del Gini }\end{array}$ \\
\hline & Kakwani & $\begin{array}{l}\text { Al resultar positivo }(0.36), \\
\text { el predial es un impuesto } \\
\text { potencialmente progresivo }\end{array}$ \\
\hline & $\begin{array}{l}\text { Gini antes y después del cobro } \\
\text { del predial por parte de los } \\
\text { municipios }\end{array}$ & $\begin{array}{l}\text { Después del cobro de predial, las } \\
\text { desigualdades en la capacidad } \\
\text { de generar recursos propios entre } \\
\text { municipios aumentan en } 22 \text { puntos } \\
\text { promedio, 2008-2012 }\end{array}$ \\
\hline & $\begin{array}{l}\text { Municipios que concentran el } \\
90 \% \text { de la recaudación del } \\
\text { predial }\end{array}$ & $\begin{array}{l}\text { El } 90 \% \text { de la recaudación del } \\
\text { predial se concentra en el } 12 \% \text { de } \\
\text { los municipios }\end{array}$ \\
\hline
\end{tabular}

FUENTE: ELABORACIÓN PROPIA. 